\title{
THOMAS BERNHARD: NOVELAS AUTOBIOGRÁFICAS
}

\author{
Silvia Herce Pagliai
}

\begin{abstract}
The aim of this article is the autobiographical account as a dominant literary theme in the austrian literatur of the 70's, which at the same time demonstrates the rejection of the prevailing tendancy, as much in literature as in austrian life and society during the post war years to re-establish once more the imperialist tradition Austria held before the second world war. The study concentrates on the austrian author Thomas Bernhard and his four autobiographical novels, works in which the author narrates to such an extent in doing so, limiting himself almost exclusively to negative experiencies, childhood memories and adolescent recollections, all of which took place under the national socialism. His obsession of looking for and telling the truth about what national socialism really meant for Austria go against those who during the post-war period preferred to forget what happened. It is translated in these works of Bernhard by the acquisition of a moralist standpoint, which is apparent in the constant criticism which paradoxically denotes a love-hate relationship the author has for his origins.
\end{abstract}

\section{La Literatura austríaca desde 1945.}

A diferencia de la literatura alemana de posguerra, la literatura austríaca posterior al año 1945 se caracteriza por un afán en pos de alcanzar la continuidad y estabilidad de la Austria de antes de la guerra. Se intenta retomar y hacer resurgir la antigua Austria, su pasado y tradición imperiales. Este hecho, que aúna tanto añoranza como anhelo por la perduración del pasado austríaco se va a plasmar en gran cantidad de escritos en los que se ensalza el hombre, el espíritu y la literatura autóctonas.

Característico de dichos años de reinicio literario en Austria es la armonía existente entre las diferentes generaciones de autores. Muestra de ello, fueron las publicaciones en 1947 en la revista Plan, revista que se consideró símbolo del nuevo comienzo de la literatura de posguerra austríaca, de Heimito von Doderer, representante de la literatura narrativa de la antigua generación, y de Herbert von Eisenreich, representante de la nueva generación de autores austríacos. Los años cincuenta, se caracterizan pues, en la literatura austríaca por este ambiente literario de tintes tradicionales y restauradores, arraigado en el pasado, en suma, en el reencuentro con la tradición austríaca.

Es a partir de los años sesenta cuando se comienzan a oir ecos de cambio: la creación del círculo literario de Viena (1952-1964), que desarrolla la llamada "Dialektdichtung"1 o poesía dialectal, supuso una ruptura con el intento de restauración tradicionalista, ya que se sirve de

\footnotetext{
${ }^{1}$ Weiss, W., Die Literatur der Gegenwart in Österreich, en: Deutsche Gegenwartsliteratur, p.608.
} 
formas lingüísticas locales y de tradiciones, pero no entendidas como un folklore literario sino, más bien, como un recurso de composición poética: "es handelt sich weniger um Gedichte im Dialekt, als mit dem Dialekt"?

Muestra de ello fue la obra de Gerhard Fritsch del año 1956, Moos auf Steinen, en la que interpretaba ese vínculo con la tradición austríaca como una restauración falsa, que bien pudiera ser viso de aferramiento al pasado como modo de enfrentamiento a la nueva situación del momento.

Esto va a constituir el inicio de la corriente literaria de los años sesenta. Años en los que el surgimiento de revistas como Wort in der Zeit (1962) y Literatur und Kritik (1966) supondrán una llamada a la desconfianza ante el peligro de caer en esta fijación por el pasado y la tradición, que conducirían a un provincianismo absurdo, como resultado de una huída ilusoria hacia el pasado.

Posteriormente, los años setenta en la literatura austríaca constituirán años en los que empieza a eclipsarse esa imagen armónica de posguerra que parecían transmitir los escritores de la antigua y nueva generaciones. Se vislumbra, más bien, un cierto distanciamiento entre los mismos, más que armonía y tolerancia. El término "Tendenzwende", aplicado en un principio en ámbitos políticos, toma ahora valor también en la literatura, y refleja, como el término indica, el cambio de tendencias que lleva a un nuevo subjetivismo; lo que en la literatura alemana configuran las obras de Peter Schneider Lenz y la obra autobiográfica Klassenliebe de Karin Struck ${ }^{4}$. El individuo ya no es considerado como ser "político", símbolo de un pueblo, cultura o tradición, sino como ser humano, como persona. Ya no son el hombre, el espíritu y alma austríacos objeto literario, sino el hombre como sujeto, de modo que este redescubrimiento del individuo lleva a la novela y a la narrativa a la introspección y reflexión. Se busca un distanciamiento de la política en la literatura, como resultado de la crisis ideológica, política y económica del momento, y ello va a tener como consecuencia la aparición de manifestaciones autobiográficas con el objeto de redescubrir el yo, de tratar cuestiones en torno a la propia identidad y la propia existencia.

La nueva tendencia general en la literatura en lengua alemana lo conforma ahora la narración autobiográfica, en la que se transmiten de manera subjetiva experiencias sociales. Autores austríacos destacados son Peter Handke, Michael Scharang, Barbara Frischmuth, y por supuesto, Thomas Bernhard.

La inclinación al género autobiográfico o a la literatura con tintes autobiográficos podría considerarse una constante dominante en la literatura en lengua alemana de los años setenta. Pero este carácter autobiográfico no se limita sólamente a describir la vida del autor durante el nacionalsocialismo, sino que plasma en las obras experiencias traumáticas vividas en una infancia y juventud sitas en dicha época. Johan Strutz destaca las obras de Peter Brückner, Christa Wolf y Thomas Bernhard por su "subjektive Authentizität"s o autenticidad subjetiva.

\footnotetext{
${ }^{2}$ Weiss,W., Die Literatur der Gegenwart in Österreich, p.608.

${ }^{3}$ ibd., p.613.

${ }^{4}$ Magallanes Latas, F., Unidad y pluralidad de la persona en la literatura alemana actual, p.18.

${ }^{5}$ Strutz, J., OWir, das bin ichO.-Folgerungen zum Autobiographienwerk von Thomas Benhard, en: In Sachen Thomas Benhard, p. 179.
} 
Se trata de autores, cuyas obras tienen en común -en el caso de Bernhard llevado a un grado extremo y limitándose casi exclusivamente a experiencias negativas- el relato de experiencias de una infancia y juventud desarrolladas en el Nacionalsocialismo.

\section{Thomas Bernhard: Breve biografía.}

Nicolaas Thomas Bernhard nació el 9 de Febrero de 1931 en Heerlen (Holanda). En otoño del año de su nacimiento, Bernhard fue llevado por su madre a Viena para vivir con sus abuelos, Anna Bernhard y el escritor Johannes Freumbichler, "den mir liebsten Menschen"6, modelo a seguir para el autor, y la figura del padre que no tuvo, así como su educador. El mismo Bernhard expresa su agradecimiento hacia él en una de sus novelas, en Der Atem: “... ihm verdankte ich alles, was mich schießlich lebensfähig und in hohem Maße auch immer wieder glücklich gemacht hatte" . De 1943 a 1944 vivió Bernhard en un internado de Salzburgo, y posteriormente, trabajó hasta abril de 1945 en un vivero en Traunstein. En el verano de 1945 vuelve a Salzburgo donde estudia en el instituto Johanneum. Al final de 1946 marcha toda la familia a vivir a Salzburgo. En 1947 interrumpe Bernhard su formación de Bachillerato y comienza un aprendizaje en una tienda de comestibles. En años posteriores y hasta 1951 su vida se desarrolla entre hospitales, balnearios y médicos, aquejado de una grave enfermedad pulmonar; años en los que vivirá la muerte de su abuelo y su madre, y hechos, todos ellos, que van a marcar definitivamente su existencia. En 1952 comienza estudios de música y arte dramático en la academia Mozarteum de Salzburgo y escribe en el periódico Sozialistische Volksblatt, para, a partir de 1957 comenzar su labor de escritor independiente.

\section{Novelas autobiográficas}

Las obras objeto del presente estudio pertenecen al citado período de los años setenta en la literatura austríaca, y son el fiel reflejo del afán característico en estos años por redescubrir el yo y su historia. Son narraciones autobiográficas que recogen la vida desde el nacimiento hasta los veinte años del autor; son años de su infancia y adolescencia. Las obras referidas son, concretamente, y por orden cronológico de edición :

Die Ursache. Eine Andeutung (1975)

Der Keller. Eine Entziehung (1976)

Der Atem. Eine Entscheidung (1978)

Die Kälte. Eine Isolation (1981)

Ein Kind (1982)

En ellas Thomas Bernhard presenta su familia, sus orígenes, experiencias traumáticas y enfermedad, y plasma su búsqueda de la verdad como motor de su creación artística literaria y su comportamiento ante la vida. Esta obsesión por la verdad se percibe en todas sus obras y constituye tanto consecuencia, como reacción frente a la tendencia restauradora de la antigua

\footnotetext{
${ }^{6}$ Bernhard, Der Atem, p.18.

${ }^{7}$ Bernhard, Thomas, Der Atem, p.26
} 
historia y tradición austríacas y su consiguiente transformación en una historia falsificada, tan extendida y fijada en la realidad, "daß man nicht mehr zwischen Schein und Sein unterscheiden könne". Schein und Sein, apariencia y realidad; la imagen del pasado austríaco es para él una imagen falsa y ensalzada, como si de un cuento se tratara, y Bernhard, el cual se autocalifica de "Märchenzerstörer" $o$ "destrozacuentos", y que podría dedicarse a ensalzar la historia de la gloriosa Austria, o de la ciudad imperial de Viena, así como del pueblo austríaco, se niega a seguir la tendencia reinante.

$\mathrm{Su}$ actitud toma tintes moralistas. Se plantea la tarea de mostrar y enfrentar al público con la realidad y verdad austríacas y, terminar con la falsa ilusión imperante. Ello queda patente en sus obras autobiográficas, en Der Keller, por ejemplo, expone la necesidad de contar la verdad, de no callar de ninguna manera las desgracias vividas con el ánimo de que ésta sean alguna vez superadas o desaparezcan: "Man darf nicht aufhören, ihnen die Wahrheit zu sagen, und die furchtbaren und entsetzlichen Wahrnehmungen, die man macht, dürfen unter keinen Umständen verschwiegen oder auch nur verfälscht werden" ${ }^{10}$.

En estas novelas autobiográficas es Austria, el Estado y pueblo austríacos, y especialmente, la política cultural del momento, objeto de sus más duras críticas. Crítica que se va a reflejar en la descripción que hace de ciudades como Salzburgo, haciendo resaltar esa hipocresía y conservadurismo de la vida diaria como mecanismo de estado:

"Die Heuchelei ist ihr (von Salzburg) Fundament, und ihre größte Leidenschaft ist die Geistlosigkeit ... Sazlburg ist eine perfide Fassade, auf welche die Welt ununterbrochen ihre Verlogenheit malt. Meine Heimatstadt ist in Wirklichkeit eine Todeskrankheit." ${ }^{11}$

La serie de narraciones autobiográficas que comienza en 1975 con Die Ursache.Eine Andeutung, a la que siguen Der Keller.Eine Entziehung (1976), Der Atem.Eine Entscheidung (1978), Die Kälte.Eine Isolation (1981) y Ein Kind (1982) constituye el redescubrimiento del yo y de su historia, reflejo del caracter introspectivo de la literatura de los años setenta. Con la primera obra se sitúa Bernhard en la Salzburgo de la época de guerra y posguerra y, con aguda ironía, caracteriza la vida entre el Nacionalsocialismo y el estricto Catolicismo que imperó posteriormente en dicha ciudad. Ciudad a la que califica de "fortaleza del miedo y del terror" de su infancia ("Die Angst- und Schreckenfestung"); la ciudad, que marcó toda su existencia y determinó su conciencia:"die sein ganzes Wesen durchsetzt und seinen Verstand bestimmt hat"12. Salzburgo se convierte en un lugar que formará parte y estructurará ese yo en un grado máximo: "... alles in mir ist dieser Stadt als Herkunft ausgeliefert". ${ }^{13}$ Cada obra gira en torno a determinados lugares de la ciudad de Salzburgo en los que se desarrolla su vida: Die Ursache refleja la etapa de su vida que transcurrió en un internado de la ciudad bajo el Nacionalsocialismo (años 1943-1946), que en 1945 pasó a ser un estricto instituto católico, dejando patente en la novela su contínua angustia y tendencia suicida al comprobar que ambas

\footnotetext{
${ }^{8}$ Fetz G., Thomas Bernhard und die österreichische Tradition, en: Österreichische Gegenwart, p.192.

${ }^{9}$ ebd., p. 172.

${ }^{10}$ Bernhard, Th., Der Keller, p.35.

${ }^{11}$ Bernhard, Th., Die Ursache, p. 10-11.

${ }^{12}$ Bernhard,Th., Die Ursache, p.8.

${ }^{13}$ ebd., p. 60.
} 
instituciones "no eran más que aunténticas prisiones"14 en las que él estaba recluído y cuya única escapatoria la ofrecía el suicidio ${ }^{15}$. En Der Keller, es la tienda de comestibles en la que trabajó de aprendiz, la que ocupa el primer plano de la narración, así como su lucha y rebeldía por ir "in die entgegengesetze Richtung"16. En Der Atem se trata del hospital en el que en 1949 estuvo internado durante meses aquejado de enfermedad pulmonar, y en el que Bernhard, desahuciado ya por los médicos, y tras la muerte de su abuelo, opta por sobrevivir ${ }^{17}$. Die Kälte tiene, de nuevo,otro sanatorio, esta vez en Grafenhof, como escenario. Bernhard sufre una recaída y ha de ser de nuevo hospitalizado, pero su afán por vivir y la composición de sus primeros poemas, junto con la certeza de querer y poder escribir como salida a sus sufrimientos son ahora el objetivo de su vida: "... meine Gedichte sind gut, Produkte eines achtzehnjährigen Verzweifelten, der außer diesen Gedichten nichts merh zu haben schien. ... ich schrieb und schrieb, ... ich existierte nur, wenn ich schrieb"18. Ein Kind, constituye la quinta y última de sus novelas autobiográficas y, a pesar de ser la última novela por orden cronológico de edición, supone la narración de sus primeros años de infancia hasta los 13 años y su ingreso en el internado de Salzburgo.

Con respecto a su técnica narrativa podrían diferenciarse varios ámbitos dentro de las autobiografías citadas. Un ámbito de narración de acontecimientos y sucesos, en el que Thomas Bernhard narra sus vivencias de la infancia, relata y habla sobre las personas que le rodearon y cuenta la historia de su familia y sus orígenes.

Un segundo ámbito de, tal vez, mayor abstracción narrativa, constituyen los comentarios del narrador. Bernhard comenta detalles en su recorrido narrativo que se refieren a sentimientos y sensaciones del yo narrador, que recuerda y al mismo tiempo matiza la situación del yo escritor.

Y un tercer ámbito, comprendería las reflexiones sobre el proceso de escritura que los comentarios del narrador presentan: se observa en las obras la presencia de citas explicativas o introductorias que se incluyen en el hilo narrativo. Esto es algo característico de la obra autobiografía de Thomas Bernhard, ese "Erzählkontinuum, das ... durch stationäre Passagen platzgreifend unterbrochen wird"19. Todo va a ser narrado en primera o tercera persona y según el orden cronológico de acontecimientos, pero aparecen, sin embargo, dos perspectivas bastante claras: de forma expresa aclara Bernhard que lo que él relata, es aquello que él entonces experimentó y sintió, no lo que él hoy, en el momento de la plasmación por escrito de su vida, piensa. No quiere de ningún modo callar su visión actual, pero en sus narraciones se esfuerza por presentar sus vivencias y sentimientos del Bernhard niño y adolescente:

"An dieser Stelle muß ich wieder sagen, daß ich notiere oder skizziere und nur andeute, wie ich damals empfunden habe, nicht wie ich heute denke, denn die Empfindung von damals ist eine andere gewesen als mein Denken heute, und die Schwierigkeit ist, in diesen Notizen

\footnotetext{
${ }^{14}$ Bernhard, Die Ursache, p.13.

${ }^{15}$ ebd., p. 19.

${ }^{16}$ Bernhard, Der Keller, p. 16

${ }^{17}$ Bernhard, Der Atem, p. 13, p.83.

${ }^{18}$ Bernhard, Die Kälte, p. 36.

${ }^{19}$ Strutz, J., OWir, das bin ich O, p. 179.
} 
und Andeutung die Empfindung von damals und das Denken von heute zu Notizen und Andeutungen zu machen, die den Tatsachen von damals, meiner Erfahrung als Zögling damals entsprechen, wenn auch wahrscheinlich nicht gerecht werden, jedenfalls will ich den Versuch machen". ${ }^{20}$

Por esta razón podríamos afirmar que en estas obras de carácter autobiográfico de Thomas Bernhard domina el punto de vista emocional y pasional del joven y adolescente Bernhard, y al mismo tiempo éste recuerdo es acompañado de comentarios del Bernhard adulto.

Afirmación que se torna en evidencia, ya que en el transcurso de la narración se alterna tanto la primera como la tercera persona ("er, der Jüngling, der 13jährige, der Gymnasiast, der junge Mensch, der Knabe...") y ésta es utilizada en aquellas situaciones en las que se reflejan los sentimientos y experiencias en la que el Bernhard adolescente se ve envuelto.

Este procedimiento de narración intercalada constituye, ciertamente, un recurso bastante utilizado en las autobiografías contemporáneas y, si con ello se ralentiza en cierto modo la dinámica de la narración (en el caso de las obras que nos ocupan, se trata de pasajes en los que se narran detalladamente determinados momentos de la vida del autor adolescente), se comunica al lector, por otra parte, una serie de hechos ordenados bajo la forma de una narración o de una biografía sintetizada o fragmentaria. ${ }^{21}$

La extrema negatividad de Bernhard queda de manifiesto en la definición que de él hace Marcel Reich-Reinicki, que lo califica como el poeta más tétrico y el más amargo profeta de la literatura en lengua alemana ("der deutschen Literatur düsterter Poet und bitterster Prophet"), así como el cantor de la enfermedad y de la muerte: "Sänger der Krankheit und der Auflösung, des Untergangs und des Todes" ${ }^{22}$. Esta extrema negatividad y amargura es la que lleva al autor a hacer de la muerte, uno de los aspectos temáticos principales - si no el principal- de su obra, y a calificar a la humanidad como una humanidad moribunda; todo ello acompañado y reflejado mediante un lenguaje de estilo manierista por excelencia.

Su lenguaje no se puede calificar de bello literariamente, sino que es más bien seco, radical y extremo, y caracterizado por la continua e insistente repetición de palabras, partes de frases o construcciones lingüísticas como recurso literario de gran efectividad. Mediante la repetición se pueden apreciar las manías y obsesiones del yo narrador:

"Ich wußte, warum ich die Beamtin im Arbeitsamt Dutzende von Karteikarten aus dem Karteikasten herausnehmen hatte lassen, ich wollte in die entgegengesetzte Richtung, diesen Begriff in die entgegengesetzte Richtung hatte ich mir auf dem Weg in das Arbeitsamt immer wieder vorgesagt, immer wieder in die entgegengesetzte Richtung, die Beamtin verstand nicht, wenn ich sagte, in die entgegengesetzte Richtung, denn ich hatte ihr einmal gesagt, ich will in die entgegengesetzte Richtung, sie betrachtete mich wahrscheinlich als verrückt, denn ich hatte tatsächlich mehrere Male zu ihr in die entgegengesetzte Richtung gesagt, wie, dachte ich, kann

\footnotetext{
${ }^{20}$ Bernhard, Th., Die Ursache, p.96.

${ }^{21}$ May, G., La autobiografía, p. 205.

${ }^{22}$ Reich-Reinicki,M., In entgegengesetzter Richtung, en: Entgegnung, p.266.
} 
sie mich auch verstehen, wo sie doch überhaupt nichts und nicht das geringste von mir weiß". ${ }^{23}$

La composición de términos cargados de connotaciones manieristas y crueles es, igualmente, un aspecto característico de la narrativa de Thomas Bernhard, así como el uso de metáforas y construcciónes metafóricas que intensifican, si cabe, su estilo radical y negativo extremo ante la vida:

"Meine Heimatstadt ist in Wirklichkeit eine Todeskrankheit, in welche ihre Bewohner hineingeboren und hineingezogen werden, und gehen sie nicht in dem entscheidenden Zeitpunkt weg, machen sie direkt oder indirekt früher oder später unter allen diesen entsetzlichen Umständen entweder urplötzlich Selbstmord oder gehen direkt oder indirekt langsam und elendig auf diesem im Grunde durch und durch menschenfeindlichen architektonisch-erzbischöflich-stummpfsinnig-nationalsozialistisch-katholischen Todesboden zugrunde."24

La influencia de los filósofos Ludwig y Paul Wittgenstein queda patente en la obra de Bernhard, sobre todo en cuanto a su concepto de lenguaje y verdad. Tío y sobrino fueron objeto de la admiración del autor, siendo el segundo, Paul Wittgenstein, a quien conoció personalmente en 1967 en uno de los sanatorios donde ambos, Bernhard y Paul, estaban internados aquejados de dolencias pulmonares. Prueba de su admiración es la obra de Thomas Bernhard Wittgensteins Neffe, en la que los considera como los dos filósofos más conocidos y memorables de la época: "...den berühmten epochenmachenden Philosophen ... der eine, Ludwig, hatte seine Philosophie zu seiner Berühmtheit gemacht, der andere, Paul, zu seiner

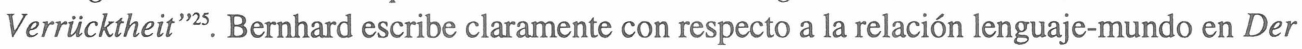
Keller: "Ich habe schon lange nicht mehr nach dem Sinn der Wörter gefragt, die alles immer nur unverständlicher machen. Das Leben an sich, die Existenz an sich, alles ist ein Gemeinplatz"26. Para Thomas Bernhard el lenguaje y el mundo son fatales, mortales: "Das Leben spricht eine kürzere, vernichtendere Sprache, die wir selbst heute sprechen... "27

Esto que Thomas Bernhard plantea sobre el lenguaje podría ser, en cierto modo, contradictorio pues no es sino mediante el lenguaje, con el que Bernhard puede expresar dicha fatalidad, pero deja siempre de manifiesto en su obra su escepticismo y crítica al respecto. Bernhard no sólo utiliza un lenguaje amenazante y en muchas ocasiones cruel, sino que juega a menudo con la palabra escrita:

"Die Sprache ist unbrauchbar, wenn es darum geht, die Wahrheit zu sagen...Die Sprache gibt nur ein gefälschtes Authentisches wider, das erschreckend Verzerrte, so sehr sich der Schreibende auch bemüht, die Wörter drücken alles zu Boden, und verrücken alles und machen die totale Wahrheit auf dem Papier zur Luge.,"28

\footnotetext{
${ }^{23}$ Bernhard,Th., Der Keller, p.16.

${ }^{24}$ Bernhard,Th., Die Ursache, p.10.

${ }^{25}$ Hrsg. Dittmar, J., Thomas Bernhard. Werkgeschichte, p. 253.

${ }^{26}$ Bernhard, Th., Der Keller, p.130.

${ }^{27}$ Bernhard, T., Der Keller, p. 131.

${ }^{28}$ Bernhard,T., Die Kälte, p. 89.
} 
Nicolaas Thomas Bernhard vivió una infancia traumática con frecuentes cambios de ciudad, así como problemas sociales debido a la situación social y económica de su familia. Sufrió penurias económicas y desgracias personales y vivió la muerte tanto de familiares allegados como de conciudadanos durante la guerra. Su carácter en la niñez y adolescencia fue siempre complicado y difícil. Era conocido por su madre como un niño terrible: "ein Schreckenskind, ein Fehltritt, ein Unfriedenstiefter"29, nos revela el propio autor en su novela Ein Kind; e igualmente, reconoce en otra de sus obras, concretamente en Der Keller:

"Ein Störenfried bin ich zeitlebens gewesen... Meine Existenz hat zeitlebens immer gestört... Alles, was ich schreibe, alles was ich tue, ist Störung und Irritierung... Die einen lassen die Menschen in Ruhe und die anderen, zu diesen andern gehöre ich, stören und irritieren." 30

\section{A modo de conclusión...}

Thomas Bernhard fallece el once de Febrero de 1989 y su voluntad final fue que su obras literarias no fueran representadas ni publicadas más en Austria:

"Ausdrücklich betone ich, daß ich mit dem österreichischen Staat nichts zu tun haben will ... Nach meinem Tod darf aus meinem eventuell gleich wo noch vorhandenen literarischen Nachlaß, worunter auch Briefe und Zettel zu verstehen sind, kein Wort mehr veröffentlicht werden." ${ }^{31}$

Esto, que supuso la emigración literaria póstuma del autor ${ }^{32}$ no ha significado en ningún momento el ser considerado un enemigo de Austria ni de lo austríaco, sino por el contrario, el ser calificado su sentimiento con respecto a sus orígenes como "Haßliebe ${ }^{\text {"33 }}$ o sentimiento de amor-odio, y su figura como "ein verschlossener Weltverbesserer, der mit klarem Kopf ... die Welt aufgemacht hat, um Abgründe sichtbar werden zu lassen. ${ }^{34} \mathrm{E}$ incluso el ser considerado, junto a Peter Handke, como el autor austríaco más famoso de su generación, "ebenso bedeutend wie schwierig". ${ }^{35}$

Este sentimiento encontrado de amor-odio que queda patente en sus obras, al igual que su dominante pesimismo y su carácter contradictorio, es consecuencia de la difícil y dura vida que le tocó vivir, y al mismo tiempo, es lo que le llevó a luchar y rebelarse ante las traumáticas experiencias vividas. Constituye además, la posibilidad de expresar la rebeldía del joven Bernhard frente a la tendencia general de olvidar y ensalzar el pasado. El querer ir a contracorriente y contar la "verdad" de lo vivido es su lema. A pesar de, como el autor aclara en su obra Der Keller, la Verdad no exista:

\footnotetext{
${ }^{29}$ Bernhard,T., Ein Kind, p.16.

${ }^{30}$ Bernhard,T., Der Keller, p. 35.

${ }^{31}$ Bernhard, T., Der Keller, p. 7.

${ }^{32}$ ebd., p.7.

${ }^{33}$ Reich-Reinicki, M., Entgegnung, p.267

${ }^{34}$ Az Journal, p. 45.

${ }^{35}$ Lennartz, F., Deutsche Schriftsteller des 20. Jahrhunderts im Spiegel der Kritik, p. 135.
} 
"Wir wollen die Wahrheit sagen, aber wir sagen nicht die Wahrheit. Wir beschreiben etwas wahrheitsgetreu, aber das Beschriebene ist etwas anderes als die Wahrheit (...) Was hier beschrieben ist, ist die Wahrheit und ist doch nicht die Wahrheit, weil es nicht die Wahrheit sein kann (...) Ich habe zeitlebens immer die Wahrheit sagen wollen, auch wenn ich jetzt weiß, es war gelogen. Letzten Endes kommt es nur auf den Wahrheitsgehalt der Lüge an (...) aber das Schreiben ist mir die Lebensnotwendigkeit, darum aus diesem Grunde schreibe ich, auch wenn alles, was ich schreibe, doch nichts als Lüge ist, die sich als Wahrheit durch mich transportiert" 36

Las obras autobiográficas de Thomas Bernhard no podrían ser calificadas de diarios ni compilaciones curriculares de su vida. Bernhard no pretende con ellas fijar de manera fidedigna y exacta las experiencias concretas vividas, sin tener en cuenta la continuidad de éstas dentro de un período de tiempo concreto, sino que, como toda obra autobiográfica requiere, el autor se mantiene a distancia, para poder narrar y reflejar desde el presente su identidad y sus experiencias en un espacio de tiempo vivido anteriormente ${ }^{37}$. Se trata de la presentación y plasmación retrospectiva de la vida del Bernhard niño y adolescente por el Bernhard adulto; y aunque los hechos narrados se correspondan con hechos vividos realmente, estas obras narrativas autobiográficas han sido consideradas textos ficticios: realidad y ficción componen el hilo narrativo; hechos reales y hechos imaginarios constituyen la trama del relato. Existen pasajes y datos en las obras tratadas que, de ningún modo, concuerdan con la realidad y que demuestran cómo Thomas Bernhard los incluye en la narración para lograr un efecto literario y artístico ${ }^{38}$. El propio autor reconoce y, en cierto modo, justifica esta mezcla de realidad y ficción al calificar sus escritos autobiográficos como simples fragmentos de su infancia y juventud, y confesar la existencia de errores o imperfecciones pero de ningún modo con ánimo de falsear la realidad:

"Es sind ihm (dem Schreiber, Bernhard) und also auch dieser Schrift,..., Mängel, ja Fehler nachzuweisen, niemals jedoch eine Fälschung oder gar eine Verfälschung,... Die Vollkommenheit ist für nichts möglich, geschweige denn für Geschriebenes und schon gar nicht für Notizen wie diese, die aus Tausenden und Abertausenden von Möglichkeitsfetzen von Erinnerung zusammengesetzt sind. Hier sind Bruchstücke mitgeteilt, aus welchen, sich wenn der Leser gewillt ist, ohne Weiteres ein Ganzes zusammensetzen läßt. Nicht mehr. Bruchstücke meiner Kindheit und Jugend, nicht mehr." ${ }^{\text {39 }}$

Esta afirmación de sinceridad e intento de contar la verdad, es considerado como una utopía en literatura autobiográfica ${ }^{40}$ por la dificultad que supone, ya que el autor escribe desde el presente y no puede escapar a éste para narrar el pasado, y para ello se sirve del recuerdo (deformado e incompleto) que guarda en su memoria. Esto es, además, dado por supuesto por el lector, el cual acepta desde el principio lo autobiográfico como fidedigno (denominado

\footnotetext{
${ }^{36}$ Bernhard, Th., Der Keller, p.38-39.

37 Gusdorf, G. Voraussetzungen und Grenzen der Autobiographie, p. 130, en: Niggl, G. (Hrsg.), Die Autobiographie, Darmstadt:Wiss.Buchges., 1989.

${ }^{38}$ Höller, H., Thomas Bernhard, p.102.

${ }^{39}$ Bernhard, Der Atem, p. 68-69.

${ }^{40}$ May, G., La autobiografía, p. 100-102.
} 
como pacto autobiográfico) y si espera del autobiógrafo este proyecto de sinceridad, no ha de engañarse sobre la oposición sinceridad/ficción que ello implica. ${ }^{41}$

Para Thomas Bernhard plasmar por escrito en estas narraciones autobiográficas su infancia y adolescencia tal y como las vivió, supuso algo totalmente necesario e inmediato. Quizás por ser consciente de su delicado estado de salud, así lo aclaraba el autor ya en la primera de sus novelas, Die Ursache :

"diese Notizen müssen jetzt notiert sein und nicht später, und zwar in diesem Augenblick, in welchem ich die Möglichkeit habe, mich vorbehaltlos in den Zustand meiner Kindheit und Jugend... zu versetzen,... dieser Augenblick, zu sagen, was gesagt werden muß, was angedeutet sein muß, muß ausgenutzt werden, der Wahrheit von damals, der Wirklichkeit und Tatsachlichkeit, wenigstens in Andeutung zu ihrem Recht zu verhelfen..." ${ }^{\text {42 }}$

\footnotetext{
${ }^{41}$ ibd., p. 215.

${ }^{42}$ Bernhard, T., Die Ursache, p. 58.
} 


\section{BIBLIOGRAFÍA}

Bernhard, Thomas, Die Ursache. Eine Andeutung, Müchen:DTV, 1993.

- Der Keller. Eine Entziehung, München:DTV, 1992.

- Der Atem. Eine Entscheidung, München:DTV, 1981.

- Die Kälte. Eine Isolation, München:DTV, 1991.

- Ein Kind, München:DTV, 1993.

Arnold,H.L.,(Hrsgb.), Text + Kritik. Zeitschrift für Literatur, Heft 43, München:Edition Text+Kritik GmbH,1991.

AZ Journal. Unabhängige Tageszeitung. Ausgabe für Wien, 2/1990.

Barsch,K. u.a.,(Hrsgb.), In Sachen Thomas Bernhard, Königstein:Athenäum, 1983.

Baulsen,W.,(Hrsgb.), Österreichische Gegenwart. Die Moderne Literatur und ihr Verhältnis zur Tradition, Bern:Francke, 1980.

Dittmar, J., (Hrsgb.), Thomas Bernhard. Werkgeschichte, Frankfurt/M.: Suhrkamp, 1990.

Durzak,M.,(Hrsgb.), Deutsche Gegenwartsliteratur. Ausgangspositionen und aktuelle Entwicklungen, Stuttgart:Reclam,1981.

Fetz, G., Thomas Bernhard und die 'österreichische Tradition, en: Österreichische Gegenwart.Die moderne Literatur und ihr Verhältnis zur Tradition, Bern : Francke Verlag, 1980.

Görtz, F.J., Hier spuckt natürlich Beckett. Thomas Bernhard und die Kritik, en: Text und Kritik, 41-44 (VIII),1981.

Höller, H., Thomas Bernhard, Reinbeck bei Hamburg:Rowohlt,1993.

Lennartz, F., Deutsche Schriftsteller des 20. Jahrhunderts im Spiegel der Kritik, Bd.I, Stuttgart : Kröner, 1984.

Magallanes Latas,F., Unidad y pluralidad de la persona en la literatura alemana actual, Madrid:Ediciones Univ. Complutense, 1988.

May, G., La autobiografía, México: Fondo de Cultura Económica, 1982.

Niggl, G. (Hrsg.), Die Autobiographie, Darmstadt : Wiss. Buchges., 1989.

Reich-Ranicki,M., Entgegnung. Zur deutschen Literatur der siebziger Jahre, Stuttgart:DTV,1981.

Sorg,B., Thomas Bernhard, München:Beck,1977.

Strutz, J., "Wir, das bin ich"-Folgerungen zum Autobiographienwerk von Thomas Benhard, en: In Sachen Thomas Bernhard, Königstein : Athäneum, 1983.

Weiss,W., Die Literatur der Gegenwart in Österreich, en: Deutsche Gegenwartsliteratur. Ausganspositionen und aktuelle Entwicklungen, Stuttgart : Reclam, 1981. 
